\title{
Critérios para premiar tradições brasileiras
}

Maria do CARMo Brant de CARVAlHo*

Em um processo seletivo, a avaliação tem o propósito de julgar o mérito de uma ação a partir de um determinado referencial valorativo, explícito e aceito pelos sujeitos que avaliam. Avaliar, portanto, significa julgar com base em um referencial de valores.

Para o processo de seleção das iniciativas inscritas na primeira edição do Prêmio Cultura Viva, buscou-se uma avaliação pautada na idéia de que a cultura na comunidade potencializa os processos de inclusão social, autonomia, empoderamento e protagonismo:

- cultura é mediação insubstituível para a construção da cidadania e o desenvolvimento sustentável das comunidades, é força na coesão social;

- cultura é conhecimento e aprendizado. Em outras palavras, em qualquer sociedade, a cultura ressignificase enquanto conhecimento e aprendizado compartilhados;

- cultura pode se transmutar em economia solidária, geração de trabalho e renda.

O Ministério da Cultura do Brasil, na gestão de Gilberto Gil, procura destacar a relação entre cultura e cidadania, potencializando as inúmeras práticas culturais desenvolvidas pela sociedade. Nesse sentido, implementou, no território brasileiro, o Programa Nacional de Cultura, Educação e Cidadania - Cultura Viva - cuja principal ação são os Pontos de Cultura.

Ao final de 2005, lançou o Prêmio Cultura Viva, com a intenção de dar visibilidade ao tamanho e à diversidade das práticas culturais que pulsam em cada canto do país. Um Brasil feito da cultura que faz o Brasil.

* Maria do Carmo Brant de Carvalho é coordenadora geral do CENPEC, doutora em Serviço Social pela Pontifícia Universidade Católica de São Paulo e pela École des Hautes Études en Sciences Sociales, Paris.
O processo de avaliação das iniciativas inscritas foi de extrema importância, pois se constituiu em um meio de mobilização e reconhecimento de práticas que resultam dos saberes e fazeres das comunidades. Assim, o processo, mais que a premiação em si, foi o "coração" do Prêmio Cultura Viva, já que permitiu que fossem alcançados objetivos maiores, como:

- o desenvolvimento de consensos para a avaliação de iniciativas culturais: avaliação participativa, realizada de modo descentralizado;

- a produção de um mapeamento nacional do "estado da arte" das iniciativas culturais;

- a indução de políticas públicas mais robustas e assertivas no que se refere ao fortalecimento da cultura, de forma abrangente, no país.

\section{As etapas de seleção do Prêmio Cultura Viva}

O processo de avaliação dividiu-se em quatro etapas:

\section{ANÁLISE PRELIMINAR}

Teve por objetivo verificar a compatibilidade das iniciativas inscritas com os requisitos definidos no Regulamento, desclassificando aquelas que não estivessem de acordo com este documento.

\section{SEleção dAS 100 INICIATIVAS SEMIfinAlistaS}

As iniciativas, classificadas na análise preliminar, foram avaliadas com base nos indicadores de análise estabelecidos no Manual de Avaliação de Iniciativas Culturais do Prêmio Cultura Viva.

Para cada regional, foi composta uma equipe de avaliadores locais que realizou a seleção a partir da leitura das fichas de inscrição e dos materiais complementares, segundo as orientações propostas no manual. 
Feita de maneira regionalizada, a seleção partiu de um critério de proporcionalidade, ou seja, o número de semifinalistas de cada regional foi proporcional ao respectivo número de inscrições em cada categoria.

\section{SELEÇÃo dAS 30 INICIATIVAS FinAliStAS}

A seleção das iniciativas finalistas foi realizada por um Comitê Técnico, com base na leitura das fichas de inscrição, dos materiais complementares e dos pareceres produzidos pelos avaliadores regionais.

O Comitê Técnico foi composto por representantes de institutos, fundações, universidades, organizações governamentais e da sociedade civil, além de profissionais de reconhecida atuação na área da cultura.

\section{SELEÇÃo NACIONAL dAS NOVE INICIATIVAS PREMIAdAS}

Fase A - Os participantes de cada uma das 30 iniciativas finalistas receberam a visita de um profissional da Comissão Técnica de Visitas, que apresentou um relatório com elementos complementares para a avaliação da Comissão Julgadora.

Fase B - Seleção das nove iniciativas vencedoras (três em cada categoria), realizada pela Comissão Julgadora, por meio da leitura das fichas de inscrição e materiais complementares, da documentação produzida pelos avaliadores regionais e pelo Comitê Técnico, além dos relatórios elaborados pela Comissão Técnica de Visitas.

\section{A análise documental e visitas técnicas}

\section{A análise preliminar, a seleção dos 100 semifinalistas e} a dos 30 finalistas foram baseadas na avaliação documental - ficha de inscrição contendo informações detalhadas de cada iniciativa inscrita e material complementar.

A análise documental conjuga duas perspectivas: uma, mais objetiva, considera as informações factuais, como conteúdo, estratégias, processo e resultados da ação; e outra, subjetiva, capta valores, atitudes, condutas, motivações e tensões.

Cada iniciativa foi analisada buscando-se compreender a sua importância no contexto em que se encontra inserida. Sem dúvida, a diversidade de experiências e de conhecimentos acumulados pelos avaliadores trouxe olhares objetivos e subjetivos também variados. Se, por um lado, isso foi um risco, por outro, constituiu a riqueza do processo avaliativo implementado.

Na quarta e última fase, foram realizadas visitas técnicas aos locais das 30 iniciativas finalistas recomendadas, para atestar os pareceres avaliativos produzidos, confirmando ou não a seleção proposta.

\section{Os avaliadores}

No processo de avaliação, a convocação de agentes sociais ligados à cultura, à política social, à gestão governamental e às organizações da sociedade civil democratizou e diversificou o olhar sobre as iniciativas cultu-

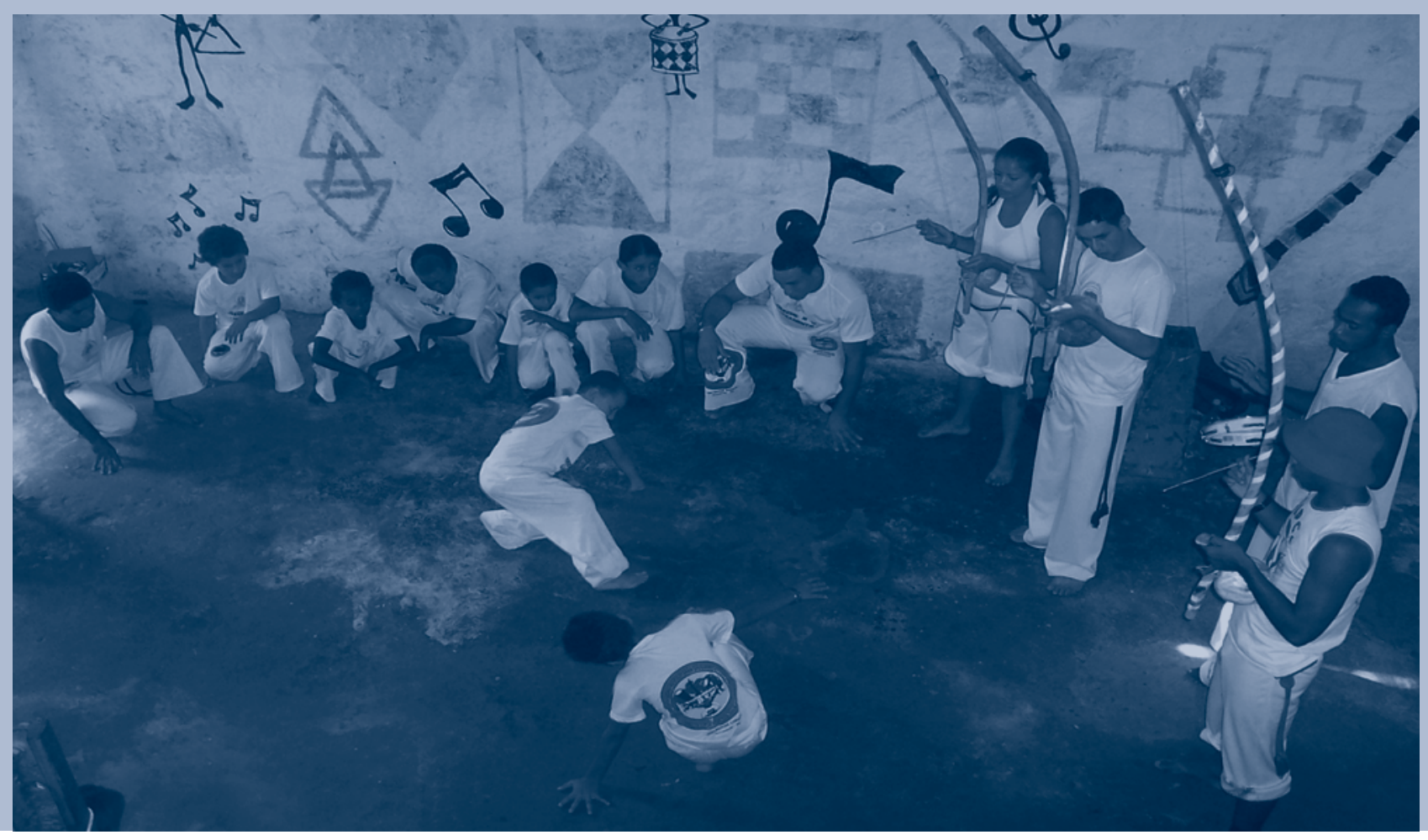


Dada a variabilidade

de sujeitos e propostas, $e$ considerando, sobretudo, a diversidade regional

e a presença dos grupos

informais, foi necessária

uma boa dose de

flexibilidade durante o

processo de seleção. Não

é possível, por exemplo, esperar portfólios completos

dos grupos informais, nem

dos apresentados pela

maioria das organizações

constituidas legalmente.

rais presentes na sociedade brasileira, tornando o processo mais participativo e transparente, e criando uma rede de parceiros na produção dos retratos de cultura deste país.

Respeitando as características socioculturais e geográficas do território, foram estabelecidas três regionais: Nordeste, Sul e Sudeste, Norte e Centro-Oeste.

Este processo gerou alguns produtos sociopolíticos da maior importância:

- valorização de práticas culturais;

- fortalecimento de políticas locais e regionais de cultura;

- desenvolvimento de competências em torno da própria avaliação de iniciativas culturais.

Precedendo o trabalho de avaliação, cabe destacar que 0572 avaliadores regionais receberam formação presencial, visando a uma discussão mais aprofundada a respeito dos critérios definidos no manual.

\section{O processo}

O Manual de Avaliação de Iniciativas Culturais do Prêmio Cultura Viva orientou a avaliação/seleção, apontando critérios e valores que seriam os parâmetros da análise das iniciativas culturais inscritas.

Se, por um lado, o manual organiza indicadores de avaliação no campo da cultura, por outro, não encerra o assunto. Ao contrário: abre possibilidades, suscita reflexões e revisões, permitindo a construção de olhares mais atentos e cuidadosos sobre a riqueza das manifestações culturais brasileiras.

Além disso, traz indicadores para avaliar, em sua totalidade, a iniciativa inscrita, situada e datada neste Brasil de regiões absolutamente distintas. Introduz, igualmente, indicadores mais específicos para cada categoria: Tecnologia Sociocultural, Manifestação Tradicional e Gestão Pública.

Dada a variabilidade de sujeitos e propostas, e considerando, sobretudo, a diversidade regional e a presença dos grupos informais, foi necessária uma boa dose de flexibilidade durante o processo de seleção. Não é possível, por exemplo, esperar portfólios completos dos grupos informais, nem dos apresentados pela maioria das organizações constituídas legalmente. Por isso, foram solicitados materiais complementares, e não portfólios.

Houve iniciativas apresentadas com documentação e escritas irrepreensiveis; outras, com lacunas documentais e redação muitas vezes incompreensível, mas que sinalizavam criatividade e potencialidade. Foram necessárias, portanto, a experiência e a sensibilidade dos avaliadores para a compreensão das várias desigualdades regionais/locais, do isolamento de muitas dessas iniciativas, sua rara presença no espaço público maior e, entretanto, sua forte inserção no espaço público das comunidades. Cultura é pertencimento. Portanto, adquire a cor e a identidade das comunidades.

Outra peculiaridade importante é a de que a cultura é expressa por meio de projetos que têm sentido multissetorial, isto é, aparece às vezes na interface com a educação ou com a área de combate à pobreza, ora como desenvolvimento local, ora, ainda, como empoderamento de grupos considerados minorias, ditadas por gênero, etnia, faixa etária...

Assim, é necessário compreender que cultura é a mediação fundamental em projetos das demais áreas de políticas públicas que visam ao exercício de cidadania, à educação popular e ao desenvolvimento local.

O parecer avaliativo/seletivo, no âmbito do Prêmio Cultura Viva, incidiu na pertinência, consistência, coerência, legitimidade e peso social da iniciativa para a comunidade, aferindo sua relevância e beleza como expressão de identidade e pertencimento à comunidade. 


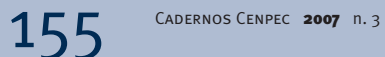

